\title{
Frontiers
}

\section{in the Psychotherapy} of Trauma \& Dissociation

\author{
Mindful Attachment: An Organic \\ Way to Work with Children Who \\ Have Been Through Complex \\ Trauma and Neglect \\ Christine Forner, MSW, RSW
}

The Official Clinical Journal of the International Society for the Study of Trauma and Dissociation 


\section{Frontiers in the Psychotherapy of Trauma \& Dissociation}

The Official Clinical Journal of the ISSTD

\section{EDITOR}

ANDREAS LADDIS, MD, Private Practice and Faculty, Boston University, School of Public Health, Boston, Massachusetts, USA

\section{ASSOCIATE EDITOR}

MARTIN J DORAHY, PhD, Professor, Department of Psychology, University of Canterbury, Christchurch, New Zealand and The Cannan Institute, Brisbane, Australia

Frontiers in the Psychotherapy of Trauma \& Dissociation is published by the International Society for the Study of Trauma and Dissociation, Inc., 1420 New York Ave NW, Fifth Floor, Washington, DC 20005.

\section{Annual Subscription, Volume 3, 2019}

Online subscription is part of the membership dues of the International Society for the Study of Trauma and Dissociation. Visit http://www.isst-d.org/default.asp?contentID=44.

Production and Advertising Office: ISSTD Headquarters, 1420 New York Ave NW, Fifth Floor, Washington, DC 20005.

Copyright @2019 International Society for the Study of Trauma and Dissociation. All rights reserved. No part of this publication may be reproduced, stored, transmitted, or disseminated in any for or by any means without prior written permission from the International Society for the Study of Trauma and Dissociation. The publisher assumes no responsibility for any statements of fact or opinion expressed in the published papers. The appearance of advertising in this journal does not constitute an endorsement or approval by the publisher, the editor, the editorial board, or the board of directors of the International Society for the Study of Trauma and Dissociation of the quality or value of the product advertised or of the claims made of it by its manufacturer.

Subscriptions to this journal are acquired through membership in the International Society for the Study of Trauma and Dissociation only.

Visit http:/ / www.isst-d.org/default.asp?contentID=45.

Permissions. For further information, please write to info@isst-d.org.

\section{EDITORIAL BOARD}

ELIZABETH S BOWMAN, MD, Editor Emerita, Journal of Trauma \& Dissociation, Adjunct Professor of Neurology, Indiana University School of Medicine, Indianapolis, Indiana, USA

LAURA S. BROWN, PhD, Private Practice, Seattle, Washington, USA

RICHARD A CHEFETZ, MD, Private Practice, Faculty and Founding Member Institute of Contemporary Psychotherapy \& Psychoanalysis, Distinguished Visiting Lecturer: William Alanson White Institute of Psychiatry, Psychoanalysis \& Psychology, New York City, USA

CONSTANCE J DALENBERG, PhD, Trauma Research Institute, California School of Professional Psychology, San Diego, California, USA

J.K. JUDITH DANIELS, PhD, Faculty of Behavioural and Social Sciences, University of Groningen, The Netherlands

STEVEN N GOLD, PhD, Professor, Center for Psychological Studies, and Founding Director, Trauma Resolution \& Integration Program, Nova Southeastern University, Fort Lauderdale, Florida, USA ELIZABETH B HEGEMAN, PhD, Professor, Department of Anthropology, John Jay College of Criminal Justice, New York, New York, USA 
RICHARD P. KLUFT, MD, PhD Private Practice and Clinical Professor of Psychiatry, Temple University School of Medicine; Faculty Member, Philadelphia Center for Psychoanalysis,

Philadelphia, Pennsylvania, USA

CHRISTA KRÜGER, MD, Professor of Psychiatry, University of Pretoria, Pretoria, Gauteng, South Africa

KARLEN LYONS-RUTH, PhD, Professor of Psychology, Harvard Medical School, Cambridge, Massachusetts, USA

ALFONSO MARTÍNEZ-TABOAS, PhD, Professor, Albizu University, San Juan, Puerto Rico

WARWICK MIDDLETON, MD, Adjunct Professor, Cannan Institute, Brisbane, Australia ELLERT

R. S. NœENHUIS, PhD, Department of Psychiatry and Outpatient Department Mental Health Care Drenthe, Assen, The Netherlands

SANDRA PAULSEN, PhD, Bainbridge Institute for Integrative Psychology, Bainbridge Island, Washington, USA

VEDAT SAR, MD, Professor of Psychiatry, Koç University School of Medicine (KUSOM), Istanbul, Turkey

JOYANNA SILBERG, PhD, Trauma Disorders Program, Sheppard Pratt Health Systems, Baltimore, Maryland, USA

ELI SOMER, PhD, Professor, School of Social Work, University of Haifa, Israel

KATHY STEELE, MN, CS, Private Practice, Atlanta, Georgia, USA

ONNO VAN DER HART, PhD Emeritus Professor of Psychopathology of Chronic Traumatization, Department of Clinical and Health Psychology, Utrecht University, Utrecht, The Netherlands VICTOR WELZANT, PsyD, Sheppard Pratt Health Systems, Trauma Disorders Program

\section{REVIEWERS}

JOHN BRIERE, PhD, Associate Professor of Psychiatry and Psychology, University of Southern California Keck School of Medicine, Los Angeles, California, USA

SHELDON IZKOWITZ, PhD, Clinical Associate Professor of Psychology and Clinical Consultant, Postdoctoral Program, New York University, New York City, USA and Teaching Faculty \& Supervisor of Psychotherapy and Psychoanalysis, National Institute for Psychotherapies, New York City, USA

MARY-ANNE KATE, PhD Researcher at University of New England, Australia; University of New England, New South Wales, Australia

ULRICH F. LANIUS, PhD, Private Practice, West Vancouver, British Columbia, Canada

\section{SUPPORTERS}

ISSTD thanks its generous supporters whose contributions have made this publication possible:

Andreas Laddis, MD, USA

\section{The \\ Cannan \\ Institute}

Cannan Institute, Australia Warwick

Middleton, MD, Australia

Dana Ross, MD, Canada

Martin J. Dorahy, PhD, New Zealand

Kate McMaugh, Australia

Sara Y. Krakauer, USA 


\title{
ARTICLE
}

\section{MINDFUL ATTACHMENT: AN ORGANIC WAY TO WORK WITH CHILDREN WHO HAVE BEEN THROUGH COMPLEX TRAUMA AND NEGLECT}

\author{
CHRISTINE FORNER, MSW, RSW
}

Associated Counselling

Small children, due to development limitations, use nonverbal communication over verbal communication, especially when they have experienced traumatic events. As more advanced verbal communication takes years to develop, most children rely on their first language of sensations, movement and emotions when communicating to and with others. This creates obvious challenges when many therapeutic modalities heavily rely on verbal communication. By examining mindfulness from a human bonding lens, one can understand that there are many functions of mindfulness that are better understood from a neurobiologicalaffect-regulation perspective than from a simple relaxation stance. By translating what is known about mindfulness into the realm of attachment, human bonding and care for our young, we can understand that mindfulness can also be seen as a skill involved in social engagement. This skill can then be utilized to effectively work with traumatized infants and small children. Mindful Attachment is intended to bridge the gap between nonverbal and verbal expression in order to help children through overwhelming and traumatic events.

KEYWORDS mindfulness, attachment, attunement, trauma, neglect, child abuse

Author Contact Information: E-mail: cf.associatedcounselling@gmail.com. 


\section{INTRODUCTION}

When one hears the term mindfulness it is not uncommon to visualize a person in a sitting position, with their eyes closed, focusing their attention to the ebb and flow of their internal experiences and thoughts. The practice of mindfulness, in the more traditional sense, is demonstrating to be an effective way to relax, calm and focus. Studies have shown that if you practice Mindfulness Meditation by utilizing the three main components of "(1) awareness, (2) of present experience, (3) with acceptance" (Germer, 2006, p. 13), you will alter the structure and function of the brain (Brenner \& Hominoff, 2004; Kang et al., 2013). Yet, this classic notion of what mindfulness is only scratches the surface of what mindfulness really does. Mindfulness is proving to be an activity that engages areas of the brain that are capable and responsible for advanced relational abilities. Mindfulness is proving to be so much more than an internal activity; it can be used to develop a grander way to communicate and relate to others. Mindfulness can be used to assist us with advanced attachment to our young. Therefore, in an effort to transform traditional mindfulness practices into a tangible therapeutic intervention, the concept of Mindful Attachment will be introduced. Mindful Attachment will be defined as using the skill of orienting and attending to the therapist's internal present experiences in order to attune to the nonverbal communication of infants and children. Mindful attachment through mindful attunement is a way that therapists can utilize natural abilities and skills of mindfulness to understand what a traumatized child is attempting to communicate when there are no words available. In many ways the following essay is a lot more about the internal experiences of the therapist rather than the experience of the infant or child.

\section{CASE EXAMPLE}

In 2017 a two-year-old, who was suspected to have been sexually assaulted, was playing in an area of my office as I was speaking with the mother. The little girl quite suddenly became very tense and stood very straight and still. She stopped playing with the stuffed animals she was previously playing with. The two-year-old then robotically walked over to the mother, sat on her mother's lap and then stared out the window. Her face went blank, and she just stared for a long while. She appeared to have been dissociating and was very vacant and relationally absent. I asked the mother how often she did this, and the mother stated that she had been doing this robotic thing a lot since the suspected event. The mother noted that the child has also not been sleeping well, displaying overt sexual actions and was needing more attention than usual. Shortly after I asked the mother if this type of behavior 
was common or frequent, and after the mother answered, the little one, quite suddenly, started to loudly, robotically, scream. It was in this moment that I felt terror inside of me.

I have been working with very traumatized individuals for a long time, and it has been a long while since I have felt fear in the office. The fear I felt in that moment was loud and clear. I was so surprised at how I was feeling that I had to take a pause and journey inside of myself to assess what this was. In this moment I utilized my own skills of mindfulness to focus my attention to the inner present moment experiences of my sensations and feelings with acceptance. It was then that I just knew, through years of selfintrospection in my personal life and also clinical settings, that I was able to assess that these intense feelings that I was having were not mine at all, they were the child's. I was, so to speak, picking up on her feelings as my own felt feelings, yet they made no sense to me, other than they "belonged" to the child. It was then that I also asked the mother how she was feeling, and she said she was terrified too.

I said that I too was having feelings of terror, but I do not think these feelings are mine; I think they are the child's. The mother was also likely hurt by the same person who hurt her child, and I realized that I had two triggered people in my room. After taking a quick mindful assessment inside of me and intentionally and mindfully calming myself down, I asked the little one if they were experiencing big scary feelings inside, and the child looked at me, nodded and said "unnhunn" in agreement. I then told the child that I could help her, as this was my job as a bigger person. I told the child that I was there to help her with the feelings that are too big for her, all the while explaining to the mother the notion of human attunement, mindful connections and the wonderment of how deeply ingrained caring for small humans can be. I explained to the mother that her child needs soothing, and we have to settle her felt feeling that she has on the insides so that she is no longer scared and crying. With the mother's help, we started to sooth the child with the sole purpose of calming her, caring for her big feelings and regulating her.

As the child sat on mom's lap, I began to rub the palms of my hands on the palms of the child's hands. I also instructed the mother to brush her hands on the child's arms, from shoulder to elbow as well as instructing the mother to rub the child's face with soft, gentle forehead to chin movements on the child's face, as well as tactile pressure on the procerus muscle on the front of the face. The touch was intended to sooth the child. The touching techniques, used in a modified way, are movements taken from Havening. Havening is a method of attempting to reconsolidate memory by de-potentiating the amygdala with the sensory input of touch. It is based on the notion that touch and distraction can alter the encoded glutamate pathways that are a result of traumatic encoding (Harper, Rasolkhani-Kalhorn, 
\& Drozd, 2009). It has been shown that there is some efficacy of Eye Movement Desensitization and Reprocessing (EMDR) based on the notion of amygdala de-potentiation (Hong, et al., 2011; Ruden, 2005, 2011). Harper et al. (2009) theorized that the bilateral movements of EMDR disrupted the activated glutamate receptors by a mechanism called de-potentiation (Ruden, 2011). Ruden continues to explain that there is data to support that serotonergic modulation of Gamma-aminobutyric acid (GABA) neurons are associated with an increase in low-frequency (delta) waves in the amygdala (Ruden, 2011). The delta waves produced during touching the face, arms and palms of the hands, while using distraction, can be an effective way to alter the previously consolidated fear responses (Ruden, 2011). For this particular case, modified Havening, where we just did the touch part on the face, arms and hands, was intended to sooth the child.

Along with soothing words, "such as you are safe here," "you are not in danger," "you are not alone," "it's okay now," "sshhhhhhh, there, there little one," from both of us and with the child's direction, we were able ask if her scary feelings were still there or if they were leaving her. I asked her if she was scared, and she again nodded in agreement that she was scared. I then asked if the soothing touch was making her feelings get bigger or smaller, and she was able to report that they were indeed getting smaller. I asked her if her scared was changing, or moving inside of her body, and she stated after the soothing words and touch that the feelings were going from being everywhere to just her tummy. Eventually they went away completely.

The mother and I cannot fill in any of the story for her, but we could calm her down; we could help the child transform her inner experience from a state of terror to a state of calm, with our explicit wording, such as asking her if what she was feeling seemed closer to fear, hunger or sleepy; she was able to identify fear. I would then follow this by saying, "Yes, you do seem very scared, and it's okay now." By identifying her feelings, based on what we were feeling and then listing possible matches that the child could agree with or disagree with, the mother was able to learn a way to regulate her child without going into the story, and to directly deal with the child's feelings and inner sensations. During our next few appointments the mother reported that the child was doing the freeze, robotic walk and trance state only occasionally, and the mom was able to settle her as quickly as we did together in my office. The mother noted that the robotic states were happening less and less.

In reviewing what had occurred, it became very clear that the skill of attunement, via mindful attachment, to the child and to myself, assisted me in being able to navigate and manage this common therapeutic situation. In other words, I used my learned skills of mindfulness to bring in my awareness of my inner sensations and experiences in order to detect and navigate what is happening to the child. 


\section{HOW MINDFULNESS CAN ENHANCE ATTUNEMENT AND FOSTER SECURE ATTACHMENT}

Mindfulness can best be described as a deep state of relaxation in which one engages in an active mental state requiring great attention (Lazar et al., 2000). It is often described as a family of self-regulation practices that involve training, attention, and awareness (Forner, 2009, 2019). The most classic definition of mindfulness is that it involves the development of awareness of present-moment experience with a compassionate, nonjudgmental stance (Kabat-Zinn, 1990). A way of practically defining mindfulness is that mindfulness is a state where the person is relaxed, engaged, focused, regulated, and aware of both internal and external experiences.

It is worth mentioning that mindfulness and mindfulness meditation are two different things that are often assumed to be the same thing (Forner, 2019). It is also fair to assume that most people envision mindfulness as mindfulness based meditations or mindfulness based therapeutic modalities such as Dialectical Behavior Therapy (DBT; Linehan, 1993), Mindfulness-Based Stress Reduction (MBSR; Kabat-Zinn, 1990), Mindfulness-Based Cognitive Therapy (MBCT; Segal, Williams, \& Teasdale, 2002) and Acceptance and Commitment Therapy (ACT; Hayes, Strosahl, \& Wilson, 1999). All of these modalities utilize the typical persona of a person in sitting position, internally focused, for 20-30 minutes at a time. This is not the mindfulness that is being referred to in this essay. There are many roads to the state of mindfulness, and the common mindfulness-based meditation is only one way. There are guided meditations, body-focused practices, such as Yoga or Tai Chi, prayer, and many other phenomena that produce the state of mindfulness. As stated, not all references to mindfulness equate to sitting meditations. Not only are there different ways to achieve the state of mindfulness, there are different mindful practices, for example, mindfulness from a Sensorimotor Psychotherapy perspective differ from a mindfulness-based practice. Ogden, Minton and Pain (2006) offer a great definition of mindfulness as:

[o]rienting and attending to the ebb and flow of the present internal experiences. Awareness and attention are directed towards the building blocks of present experiences: thoughts, feelings, sensory perceptions, inner body sensations, muscular changes, and movement impulses as they occur in the here and now (Ogden et al., 2006, p. 193).

Mindfulness involves activity in brain networks that facilitates selfawareness, body regulation and emotion regulation (Doll, Hölzel, Boucard, Wohlschläger, \& Sorg, 2015; Farb, Segal, \& Anderson, 2013; Young et al., 2018). These prominently include the medial prefrontal cortex (mPFC) and the posterior parietal cortex in the Default Mode Network, as well as the amygdala and insula in the Stress/Salience Network (Farb et al., 2013; Forner, 2019; Hölzel et al., 2007; Hölzel, Carmody et al., 2011; Hölzel, Lazar 
et al., 2011; Kang et al., 2013; Lazar et al., 2000, 2005; Luders, Toga, Lepore, \& Gaser, 2009; Siegel, 2007, 2010). When discussing Mindful Attachment, what is being referred to when speaking of this type of mindfulness is the end result of what specific brain structures do. The structures mentioned above, when utilized frequently "grow to be predominate" inside someone's brain. Which in turn effect the function that produces and promote internal and external awareness of self and others in a compassionate, nonjudgmental, one step removed, objective, present moment focused way of being (Young et al., 2018).

Siegel (2007) describes that mindfulness practices engage the same areas of the brain that are affected by relationships (Snyder, Shapiro, \& Treleaven, 2012). The Mirror Neuron system, which is also influenced by mindfulness, is a "system that takes information and signals from another person and then adjusts our limbic and bodily states in order to match those of another" (Snyder et al., 2012, p. 713). In ordinary consciousness this natural process goes on without our awareness, which may or may not be working at its full capacity. When you add in the skill of mindfulness you become aware of this process; you can feel it, sense it and know that it is occurring. When mindfully attaching to the child, the therapist's own internal world is as present as the internal world of the child. Being mindful is a way to have clear self-reflection, with inner awareness, and acceptance that defines the therapeutic intervention. The concept of the therapist being aware of their own internal state is one of the main foundational concepts in understanding and utilizing mindful attachment. Simply stated, there is a potential inside all of us, that heavily influences and is driven by our social engagement system, which gives us the structural and functional potential to be compassionate, empathic, attuned, and objective towards ourselves and others. We are all, or we should all be, hardwired for compassion, non judgemental, focused attunement and attachment. This is the advantage that mindfulness provides when working with small humans who have yet to learn the skill of spoken language, but who still need to communicate their internal worlds. In developing the skill of mindfulness, the therapist will enhance nine different skills that foster an attachment style that aligns with mindful practices and outcomes.

There are, according to Siegel (2007), nine different discrete functions that are affected by being mindful. These functions, when used together, result in internal attunement with mirroring and empathy that creates a very well-regulated state that is able to differentiate between the awareness of self and the awareness of others (Snyder et al., 2012). These nine basic functions can best be understood from a bottom-up, body-to-mind perspective. The nine functions, listed below, are similar but also different and they seem to develop from more simple or primary purpose to more complex and abstract utility. 
The first item that mindfulness affects and assists in is being able to regulate our bodies. This translates into adults being able to calm themselves down or motivate themselves up. Body Regulation is being able to, by our own ability, with intentionality, regulate our fear. This includes being able to understand the function of the fear in order to meet the need that the fear is bringing to our attention. It enables us to be able to care for those things that the fear response is concerned with (Diorio, Viau, \& Meaney, 1993; Kalisch \& Gerlicher, 2014; Motzkin, Philippi, Wolf, Baskaya, \& Koenigs, 2015; Panksepp, 1998, 2003). In the situation with the child and mother, I was able to instantly calm my body down. I was able to recognize my fear feelings, assess the source of the feelings and then regulate my own feelings of terror. I took a quick, deep breath, and on the exhale brought my attention to my internal being and then settled my facia and muscles. I also brought my attention to the front of my face in order to engage my mPFC. When my mPFC became engaged, I instantly could feel my physical body settling down. In exercising my own mindfulness, I was able to assess, with acceptance of the present moment and then instantly settle down. This whole process took less that five seconds.

The second function is the ability to regulate our emotions. Emotions seem to be one of the most challenging parts of being a human. Emotions can cripple us, and they can be so intense and painful that they can lead to dissociation and the need to split our sense of self or identity. Emotional pain can be the bane of someone's existence. There is a very necessary function of emotions, as they are our first language and the most accurate form of interpersonal communication. Emotions are what we use when we have no words or when we are too young to understand words. Emotions are part of our relational being, and we are designed to learn in childhood and adolescence how to manage them. The brain's Default Mode Network and Stress/Salience Network are active and interconnected when we are regulating, articulating and expressing our emotions with intelligence (Doll et al., 2016). The ability to be mindful helps us in being one step removed and curious to what our emotions are doing for us. This is one of the most beneficial aspects to mindfulness. When we have learned the skill of affect tolerance in the form of developing mindfulness, we can grow the ability to know why we are feeling what we are feeling with validity, and without shame (Lee, Heller, Van Reekum, Nelson, \& Davidon, 2012; Kellogg, 2013; Kolb \& Whishaw, 2004; Martelli, Chester, Brown, Eisenberger, \& DeWall, 2018). Mindfulness can also help us in differentiating and distinguishing our emotions from the emotions of others. Mindful attunement and attachment can enhance our ability to understand the communication being sent to us from our young (Snyder et al., 2012). In this situation with the child, being mindfully attached helped me in knowing very quickly that these feelings did not originate because of something I was experiencing but rather something the child was experiencing. I also utilized mindfulness 
to be one step removed from the terror that I first felt. Without the skill of mindfulness, I could have easily interpreted the fear as mine and withdrew my attention and attachment to the child, and solely focused on myself. By being able to instantly mindfully assess the source and context of my feelings, I was able to alter what I was detecting, via emotional communication, and calm down. I was then able to take my focus from myself and place all of the attention and focus on the child.

The third function of mindfulness is that it assists with response flexibility. Response flexibility is the ability to be one step removed and flexible with our reactions. It is taking a mental pause, as I did with the child (Siegel, 2007), in order to gain perspective and insight into things that are occurring in the present moment, rather than information from past experiences. Response flexibility, when we are in a mindful state, can promote a flexible reaction (Siegel, 2007). Mindfulness helps us cultivate the ability to pause what is happening inside of us. It is the ability to ask questions or gather information before reacting. This is valuable in raising our young and not getting "dragged under" by another's dysregulation (Alexander \& Brown, 2011; Cahn \& Polich, 2013; Diorio et al., 1993; Farb et al., 2007; Forner, 2019; Lee et al., 2012; Siegel, 1999).

The fourth function of mindfulness is that it can promote the regulation of conditioned fear responses. In the simplest of concepts, this is the ability to continuously, with purpose, update our learned experiences. It is our experiences that provide information on how we "live" through life. Our experiences are the main influencer of how we make meaning. Mindfulness also assists with adjusting our procedurally-learned information. It is how we change something that was procedurally learned. When something has been procedurally learned, it is information that has moved from the conscious to the unconscious, and mindfulness gives us the ability to be more purposeful with the unconscious and less automatic with our reactions and reactive responses. The underlying brain structures, when well developed, enable us to put our fears into perspective as well as regulate these fears and express them with balance and in proportion to the present context (Alexander \& Brown, 2011; Cahn \& Polich, 2013; Diorio et al., 1993; Farb et al., 2007; Lee et al., 2012; Siegel, 1999). As an example, when the child became terrified, I was able to hone in fairly quickly that these were not my feelings. There is the possibility that without the skill of mindfulness I might have associated these feelings with an experience I have had in the past and been triggered myself. The skill of mindfulness assisted in helping me mind my own self, recognize that I was okay and this was not really about me, and then focus my whole attention to the child.

The fifth function is that mindfulness helps and fosters attuned communication. Attuned communication is one of the cornerstones of Mindful Attachment. Attuned communication is the ability to send a message, know that the message has been received and to also know what the unspoken 
aspects within the messages, all the while being aware of both the implicit and explicit information. It is not just communication where language is exchanged between two people. Attuned communication is the ability to send a message and to know the emotional content of the message sent from someone else to you. It is the ability to make inferences and closeenough guesses as to what others are feeling and communicating. It is also the ability to transmit and communicate information that is less obvious than spoken words (Forner, 2019; Montgomery, 2013; Ogden, 2012; Ogden \& Fisher, 2015; Ogden et al., 2006; Schore, 1994, 2003a, 2003b). This mindful skill enables us to be one step removed from others' emotions. This ability, in many ways, helps us understand what our offspring need to communicate when they lack the ability to use verbal language (Forner, 2019). Mindfulness, or the functions of the mPFC and other brain structure, assists us in helping to feel others' feelings, but add in "this is their emotional state, not mine" (Alexander \& Brown, 2011; Cahn \& Polich, 2013; Diorio et al., 1993; Forner; 2019; Farb et al., 2007; Lee et al., 2012; Siegel, 1999). The child is not able to clearly articulate to me in any way that she is feeling scared. She is, however, capable to feel these feelings and then transmit these feelings to others. It is the job, so to speak, of the mPFC and other brain structures that become well developed when practicing mindfulness, to detect these feelings within our young and even possibly in others who are too scared to communicate in a logical and or articulate way.

The sixth function of mindfulness is empathy. We are creatures that are extremely dependent at the beginning of our lives, and somehow, we need to learn and mature to be effortlessly selfless when we become an adult. Traveling from dependence to inter-dependence and selfish to selfless is a complicated expedition, and mindfulness helps with the journey. Mindfulness promotes empathy, and empathy is part of what helps us go from an egocentric infant to an altruistic adult. The brain networks involved in mindfulness or mindful attachment can assist us in order to help with an impressive level of empathy (Farb et al., 2007, 2013; Forner, 2019). Empathy helps us understand what others feel, but when you add in mindful empathy it can support us in not reacting to others emotional activation. Mindfulness can result in a sense of care and compassion of others' feelings and perspectives, which helps us have further information rather than just an emotional reaction. Being relationally and emotionally intimate is a very risky endeavor. The mental skill of being able to feel what others are feeling in order to communicate our experience in a nonverbal way, and then to feel those feelings but be one step removed, is very challenging. It is a grand skill to know that what your own feelings are and where they come from or what they are tying to communicate, but to assess the same knowledge about someone else is very sophisticated (Perry \& Szalavitz, 2010; Porges, 1998; Tronick \& Beeghly, 2011). Mindful Attachment assists in fostering these deep, safe and intimate exchange of human communications that are 
nonverbal. Empathy is very important in raising our homo sapient offspring. We are hardwired to bond with our infants; this deep bond comes with a great deal of vulnerability. Mindfulness can assist with the intensity of this bond and vulnerably. It can help with managing the length of time it takes to raise a human as well. It takes a long time for a human to learn to logic or reason, even longer to master and be at one with our reactions. When we utilize mindfulness within a therapeutic session, we can develop the skill of being empathic and compassionate to our clients' feelings and experiences without being dragged under ourselves. As with the child, I was able to easily calm and settle myself down and, in a way, think very clearly about what was happening in the room to the child. I was able to use my higher processing to understand her experiences. I was able to understand that this is a child's experiences, not my own personal experiences.

Human infants are mostly running on instinct that is more aligned with our ancient hunter/gather evolutionary selves rather than a modernized creature of the industrialize age. Instinct is ancient understanding, and being at one with these instincts is an extremely complex process. Mindful Attachment is the process of being able to put cognition through awareness to the instinctual aspect of our being but is also so much more. Siegel (2007) states that parent or practitioner can learn to suspend ordinary tendencies to alter experiences, emotions and sensations that are painful and learn to accept these emotions and sensation of others. Though paying attention to painful emptions and sensations may seem counter intuitive, it actually assists us in eliminating them. It is through the deep acceptance to what is occurring in the present moment, the suffering gets released (Siegel, 2007; Snyder et al, 2012). It is in part due to my mindful practices that I was able to focus on the soothing of the child rather than her pain, as I was not overwhelmed by the suffering that this child was experiencing. I was able to know that she is having feelings, and these feelings were communicating her fear. I was also able to help her eliminate these feelings and replace them with feelings of safety and security in others.

The seventh function of being mindful or practicing mindfulness is that it assists with clarifying insight. Mindfulness involves insight (Farb et al., 2007; Farb et al., 2012) and introspection and understanding neuroception (Porges, 1998, 2003, 2011). The underlying brain structures that are involved in mindfulness and relating are responsible for being able to apply logic to our internal reactions. Mindfulness promotes curiosity about why we are reacting from a physical place in our bodies, like our gut or heart. This allows us to gather information about the past, present, and possible future, in a nonreactive but informative manner (Forner, 2019). It is a reflective process that involves examining oneself from the inside. It involves the mental awareness of what it is like inside. It involves being able to interpret our more mammalian responses with our unique human elucidation. With mindfulness, we can analyze information as to what the source of 
the somatic or body response is, and then gather the information and act accordingly, with action or an emotional response. In the case of the child and myself, I was able to move to a place of safety for her because I was able to find safety within myself. I was able to ground and share this grounding with the mother and the child. Insight helps with a greater understanding that seems to come with a huge amount of compassion and nonjudgement. I was able to easily understand that this child needs my adult help in order to regulate her inner reactions to a past event.

The eighth function of mindfulness is understanding and being nonjudgemental of our instinct and intuition. Mindful Attachment helps to put instinct and intuition into the correct words, meaning and proper context (Marks-Tarlow, 2012; Ogden, 2009). Placing the proper label on what we are internally experiencing is a major component to being safe in this world. This skill starts in infancy, where our caregivers are supposed to mostly or closely know what is happening inside of us and assist with externalizing the internal. Mindful Attachment helps with giving the correct meaning to our more primitive reactions. Mindfulness seems to be there so that these internal reactions make sense and/or so we can learn about what the instinct is communicating, both within ourselves and in terms of information coming from others. For the child I was able to move my focus from myself and bring it to the child. I was no longer feeling fear, so my safety was not in jeopardy, but for the child, her felt sense of safety was in jeopardy. In being mindful I was able to use a felt sense of security and pass it along to the child by using soothing words and soothing touch.

The fascinating aspect to all the above eight functions is that it fosters the ninth function. A direct side effect to practicing mindfulness, which is also the same function that seem to be part of relating to others, is that when you put all of the above functions together you end up with someone who is very calm, wise and empathic (Brenner \& Homonoff, 2004; Martelli et al., 2018). When we exercise the brain structures that are involved in mindfulness you will have a human who is able to attune to themselves and to others in a very compassionate, nonjudgmental way. These structures create presence, and it is this presence that enhances one's availability to receive whatever the person brings into the relationship. Mindfulness assists the parent, caregiver, teacher, or therapist to be aware of themselves and the other. In many ways mindfulness assists with not only the individuals own awareness, but it adds a deeper more objective awareness of ones own awareness (Siegel, 2007; Snyder et al., 2012). This multilayer awareness leads to a global sense of objectiveness that supports nonreactive experiencing and processing.

This therapist/caregiver/adult who is able to develop and maintain the state of mindfulness is enhancing the therapeutic role as they are able to be very well regulated, have a great deal of insight, can emotionally stay calm and curious, and could potentially be a baseline within every session. 
This state of being mindful and the state of mindfulness likely are also the state that our infants' and young children's primitive brains seem to be expecting from us (Alexander \& Brown, 2011; Brach, 2006; Doidge, 2007; Farb et al., 2012; Finger et al., 2008; Hölzel, Carmody et al., 2011; Luders et al., 2009; Milutinovic, Zhuang, Niveleau, \& Szyf, 2003).

Mindful Attachment translates into being very present and aware of our inner feelings, thoughts, experience, as well as being aware and present of other people's thoughts and feelings. Mindful Attachment is an organic, natural way to work with infants and children (Bögels, Hellemans, Van Deursen, Römer, \& Van Der Meulen, 2014). It assists in being able to efficiently interpret the communication from our tiny humans. Mindfulness really is a part of our human attachment system. It is the foundation for healthy human attachment, growth and development (Austin, 1998; Brenner \& Homonoff, 2004; Forner, 2019). As humans feel better with safe and secure attachments, it is logical to infer that the benefits of a secure attachment system and the benefits of mindfulness are much the same (Siegel, 2007). The well-working mindful therapist is likely a relational benefit within the counseling process. Learning and ultimately apply mindfulness to your practice will not only assist you as the therapist in gaining deeper relational security for the client, but mindfulness can also assist with understanding and intuiting your own inner experiences within the clinical session.

When the child in my office screamed and communicated terror via emotional projection, I was able to understand that these feelings were not mine, but the child's. This process of mindful awareness to my own self, in relation to the child, also examined my own possible projection or assumptions from my own lived experiences. Instead I was able to know that even though it felt exactly like my own fear, I was not feeling these feeling because of me, but rather picking up her feelings. I was able to know that what she was communicating was received loud and clear and will be addressed. It is my hope that the relational nature of mindfulness becomes better known, as it is potentially a beautiful assist to any therapist working with children, of all ages.

\section{REFERENCES}

Alexander, W., \& Brown, J. (2011). Medial prefrontal cortex as an action-outcome predictor. Journal of Nature Neuroscience, 14(10), 1338-1346. https://doi.org/10.1038/nn.2921

Austin, J. (1998). Zen and the brain: Toward an understanding of meditation and consciousness. Cambridge, MA: MIT Press.

Bögels, S., Hellemans, J., Van Deursen, S., Römer, M., \& Van Der Meulen, R. (2014). Mindful parenting in mental health care: Effects on parental and child psychopathology, parental stress, parenting, coparenting and marital functioning. Mindfulness, 5(5), 536-551. https:/ / doi.org/10.1007/s12671-013-0209-7 
Brach, T. (2006). Meditation, emotional healing and spiritual transformation: Guidelines for introducing meditation practices of psychotherapy clients. In Meditation in psychotherapy (pp. 31-33). Boston, MA: Harvard Medical School, Department of Psychiatry, Cambridge Health Alliance.

Brenner, M., \& Homonoff, E. (2004). Zen and clinical social work: A spiritual approach to practice. Families in Society: The Journal of Contemporary Social Services, 85(2), 261-269. https: / / doi.org/10.1606/1044-3894.315

Cahn, B. R., \& Polich, J. (2013). Meditation states and traits: EEG, ERP and neuroimaging studies. Psychology of Consciousness: Theory, Research, and Practice, 1(S), 48-96.

Diorio, D., Viau, V., \& Meaney, M. (1993). The role of the medial prefrontal cortex (cingulate gyrus) in the regulation of hypothalamic-petuitary-adrenal response to stress. Journal of Neuroscience, 13(9), 3839-3847.

Doidge, N. (2007). The brain that changes itself: Stories of personal triumph from the frontiers of brain science. New York, NY: Penguin Books.

Doll, A., Hölzel, B. K., Boucard, C. C., Wohlschläger, A. M., \& Sorg, C. (2015). Mindfulness is associated with intrinsic functional connectivity between default mode and salience networks. Frontiers in Human Neuroscience, 25(9), 461. https://doi.org/10.3389/fnhum.2015.00461

Doll, A., Hölzel, B. K., Mulej Bratec, S., Boucard, C. C., Xie, X., Wohlschläger, A. M., \& Sorg, C. (2016). Mindful attention to breath regulates emotions via increased amygdala-prefrontal cortex connectivity. Neuroimage, 134, 305-313. https:/ / doi.org/10.1016/j.neuroimage.2016.03.041

Farb, N. A., Segal, Z. A., \& Anderson, A. K. (2013). Attentional modulation of primary interoceptive and exteroceptive cortices. Cerebral Cortex, 23(1), 114-126.

Farb, N., Segal, Z., Mayberg, H., Bean, J., McKeon, D., Fatima, Z., \& Anderson, A. (2007). Attending to the present: Mindfulness meditation reveals distinct neural modes of self-reference. SCAN, 2(4), 313-322.

Finger, E., Marsh, A., Mitchell, D., Reid, M., Sims, C., Budhani, S., . . Blair, J. (2008). Abnormal ventromedial prefrontal cortex function in children with psychopathic traits during reversal learning. Archives of General Psychiatry, 65(5), 586-594. https://doi.org/10.1001/archpsyc.65.5.586

Forner, C., (2009). Psychotherapeutic creative, concentration and contemplation meditation: Examining a treatment option for clients who have dissociative identity disorder (Unpublished Master's Thesis for the Faculty of Social Work). University of Calgary, Calgary, Alberta, Canada.

Forner, C. (2019). What mindfulness can learn about dissociation and what dissociation can learn from mindfulness. Journal of Trauma $\mathcal{E}$ Dissociation, 20(1), 1-15. https:/ / doi.org/10.1080/15299732.2018.1502568

Germer, C. (2006). Why meditate? Which method? In C. Germer, J. Plat, \& R. Siege (Eds.), Meditation in psychotherapy (pp. 13-30). Boston, MA: Harvard Medical School, Department of Psychiatry, Cambridge Health Alliance.

Harper, M., Rasolkhani-Kalhorn, T., \& Drozd, J. (2009). On the neural basis of EMDR therapy: Insights from qEEG studies. Traumatology, 15(2), 81-95. https://doi.org/10.1177/1534765609338498

Hayes, S., Strosahl, K., \& Wilson, K. (1999). Acceptance and commitment therapy: An experiential approach to behavior change. New York, NY: Guilford Press. 
Hölzel, B. K., Carmody, J., Vangel, M., Congleton, C., Yerramsetti, S. M., Gard, T., \& Lazar, S. W. (2011). Mindfulness practice leads to increases in regional brain gray matter density. Psychiatry Research, 191(1), 36-43. https://doi.org/10.1016/j.pscychresns.2010.08.006

Hölzel, B., Lazar, S., Gard, T., Schuman-Oliver, Z., Vago, D., \& Ott, U. (2011). How does mindfulness meditation work? Proposing mechanisms of action from a conceptual and neural perspective. Perspectives on Psychological Science, 6(6), 537-559. https://doi.org/10.1177/1745691611419671

Hölzel, B., Ott, U., Hempel, H., Hackl, A., Wolf, K., Stark, R., \& Vaitl, D. (2007). Differential engagement of anterior cingulate and adjacent medial frontal cortex in adept meditators and non-meditators. Neuroscience Letters, 421(1), 16-21. https://doi.org/10.1016/j.neulet.2007.04.074

Hong, I., Kim, J., Lee, J., Park, S., Song, B., Kim, J., ... Choi, S. (2011). Reversible plasticity of fear memory-encoding amygdala synaptic circuits even after fear memory consolidation. PLOS ONE, 6(9), e24260. https:/ / doi.org/10.1371/journal.pone.0024260

Kabat-Zinn, J. (1990). Full catastrophe living: Using the wisdom of your body and mind to face stress, pain, and illness. New York, NY: Dell Publishing.

Kalisch, R., \& Gerlicher, A. (2014). Making a mountain out of a molehill: On the role of the rostral dorsal anterior cingulate and dorsomedial prefrontal cortex in conscious threat appraisal, catastrophizing, and worrying. Neuroscience and Biobehavioural Reviews, 42, 1-8. https://doi.org/10.1016/j.neubiorev.2014.02.002

Kang, D. H., Jo, H. J., Jung, W. H., Kim, S. H., Jung, Y. H., Choi, C. H., . . Kwon, J. S. (2013). The effect of meditation on brain structure: Cortical thickness mapping and diffusion tensor imaging. SCAN, 8(1), 27-33.

Kellogg, R. T. (2013). The making of the mind: The neuroscience of human nature. New York, NY: Prometheus Books.

Kolb, B., \& Whishaw, I. (2004). An introduction to brain and behaviour (2nd ed.). New York: NY: Worth Publishers.

Lazar, S., Bush, G., Gollub, R., Fricchione, G., Khalsa, G.., \& Benson, H. (2000). Functional brain mapping of the relaxation response and meditation. Neuroreport, 11(7), 1581-1585. https:/ / doi.org/10.1097/00001756-200005150-00042

Lazar, S., Kerr, C., Wasserman, R., Gray, J., Greve, D., Treadway, M., ... Fischl, B. (2005). Meditation experience is associated with increased cortical thickness. Neuroreport, 16(17), 1893-1897. https://doi.org/10.1097/01.wnr.0000186598.66243.19

Lee, H., Heller, A., Van Reekum, C., Nelson, B., \& Davidon, R. (2012). Amygdala prefrontal coupling underlies individual differences in emotion regulation. NeuroImage, 62(3), 1575-1581. https://doi.org/10.1016/j.neuroimage.2012.05.044

Linehan, M. M. (1993). Cognitive-behavioral treatment of borderline personality disorder. New York, NY: Guilford Press.

Luders, E., Toga, A. W., Lepore, N., \& Gaser, C. (2009). The underlying anatomical correlates of long-term meditation: Larger hippocampal and frontal volumes of grey matter. NeuroImage, 45(3), 672-678. https:/ / doi.org/10.1016/j.neuroimage.2008.12.061 
Marks-Tarlow, T. (2012). Clinical intuition in psychotherapy: The neurobiology of embodied response. New York, NY: W. W. Norton \& Company.

Martelli, A., Chester, D., Brown, K., Eisenberger, N., \& DeWall, N. (2018). When less is more: Mindfulness predicts adaptive affective responding to rejection via reduced prefrontal recruitment. Oxford University Press. Retrieved June 19, 2018, Social Cognitive and Affective Neuroscience, 13(6), 648-655. https:/ / doi.org/10.1093/scan/nsy037

Milutinovic, S., Zhuang, Q., Niveleau, A., \& Szyf, M. (2003). Epigenomic stress response. Knockdown of DNA methyltransferase 1 triggers an intra-S-phase arrest of DNA replication and induction of stress response genes. Journal of Biological Chemistry, 278(17), 14985-14995. https:/ / doi.org/10.1074/jbc.M213219200

Montgomery, A. (2013). Neurobiology essentials for clinicians: What every therapist needs to know. New York, NY: W. W. Norton \& Company.

Motzkin, J., Philippi, C., Wolf, R., Baskaya, K., \& Koenigs, M. (2015). Ventromedial prefrontal cortex is critical for the regulation of amygdala activity in humans. Biological Psychiatry, 77(3), 276-284.

Ogden, P. (2009). Emotion, mindfulness, and movement: Expanding the regulatory boundaries of the window of affect tolerance. In D. Fosha, D. Siegel, \& M. Solomon (Eds.), The healing power of emotion: Affective neuroscience, development $\mathcal{E}$ clinical practice (pp. 204-231). New York, NY: W. W. Norton.

Ogden, P. (2012). Beyond conversation in sensorimotor psychotherapy: Embedded relational mindfulness. In V. M. Follette, D. Rozelle, J. W. Hopper, D. I. Rome, \& J. Briere (Eds.), Contemplative methods in trauma treatment: Integrating mindfulness and other approaches. New York, NY: Guilford Press.

Ogden, P., \& Fisher, J. (2015). Sensorimotor psychotherapy: Interventions for trauma and attachment. New York, NY: W. W. Norton \& Company.

Ogden, P., Minton, K., \& Pain, C. (2006). Trauma and the body: A sensorimotor approach to psychotherapy. New York, NY: W. W. Norton \& Company.

Panksepp, J. (1998). Affective neuroscience: The foundations of human and animal emotions. New York, NY: Oxford University Press.

Panksepp, J. (2003). At the interface of the affective, behavioral, and cognitive neurosciences: Decoding the emotional feelings of the brain. Brain and Cognition, 52(1), 4-14. https://doi.org/10.1016/S0278-2626(03)00003-4

Perry, B. D., \& Szalavitz, M. (2010). Born for love: Why empathy is essential-and endangered. New York, NY: HarperCollins Publishers.

Porges, S. W. (1998). Love: An emergent property of the mammalian autonomic nervous system. Psychoneuroendocrinology, 23(8), 837-861. https: / / doi.org/10.1016/S0306-4530(98) 00057-2

Porges, S. W. (2003). The polyvagal theory: Phylogenetic contributions to social behavior. Physiology \& Behavior, 79(3), 503-513. https:/ / doi.org/10.1016/S0031-9384(03)00156-2

Porges, S. W. (2011). The polyvagal theory: Neurophysiological foundations of emotions, attachment, communication, and self-regulation. New York, NY: W. W. Norton \& Company.

Ruden, R. A. (2005). A neurological basis for the observed peripheral sensory modulation of emotional responses. Traumatology, 11(3), 145-158. https:/ / doi.org/10.1177/153476560501100301 
Ruden, R. (2011). When the past is always present: Emotional traumatization, causes, and cures. New York, NY: Routledge.

Schore, A. (1994). Affect regulation and the origin of the self. Mahwah, NJ: Lawrence Erlbaum Associates, Inc., Publishers.

Schore, A. (2003a). Affect regulation and the repair of the self. New York, NY: W. W. Norton \& Company.

Schore, A. (2003b). Affect dysregulation and disorders of the self. New York, NY: W. W. Norton \& Company.

Segal, Z. V., Williams, J., \& Teasdale, J. (2002). Mindfulness-based cognitive therapy for depression: A new approach to preventing relapse. New York, NY: Guildford Press.

Siegel, D. (1999). The developing mind: How relationships and the brain interact to shape who we are. New York, NY: Guilford Press.

Siegel, D. (2007). The mindful brain: Reflection and attunement in the cultivation of well-being. New York, NY: W. W. Norton \& Company.

Siegel, D. (2010). Mindsight: The new science of personal transformation. New York, NY: Bantam Books.

Snyder, R., Shapiro, S., \& Treleaven, D. (2012). Attachment Theory and Mindfulness. Journal of Child and Family Studies, 21(5), 709-717. https://doi.org/10.1007/s10826-011-9522-08

Tronick, E., \& Beeghly, M. (2011). Infants' meaning-making and the development of mental health problems. American Psychologist, 66(2), 107-119. https:/ / doi.org/10.1037/a0021631

Young, K. S., Van Der Velden, A. M., Craske, M. G., Pallesen, K. J., Fjorback, L., Roepstorff, A., \& Parsons, C. E. (2018). The impact of mindfulness-based interventions on brain activity: A systematic review of functional magnetic resonance imaging studies. Neuroscience and Biobehavioral Reviews, 84, 424-433. https:/ / doi.org/10.1016/j.neubiorev.2017.08.003 